DOI https://doi.org/10.18551/rjoas.2018-08.14

\title{
THE EFFECT OF EMOTION ON ENTERPRISE RESOURCE PLANNING SYSTEM QUALITY WITH USER EXPERTISE AS MODERATION VARIABLE
}

\author{
Elfita Rizki Amalia \\ Department of Accounting, Faculty of Economics and Business, University of Airlangga, \\ Surabaya, Indonesia
}

\begin{abstract}
The purpose of this research is to find out how the quality of Enterprise Resource Planning (ERP) system data is affected by the user's emotional response and to find out whether the user's expertise is able to reduce the emotional influence on the data quality of the ERP system. Data from this study were obtained through 40 questionnaires distributed to employees of ERP system users working at PT Pembangunan Pemerintah Tbk which is one of the ERP user companies in Indonesia. The results of this study found that the user's emotional variables do not affect the quality of system data. It can be seen based on $p$ values of 0.191 where the value is greater than 0.05 . Whereas for the user expertise variable has a significant positive effect on the quality of the system data. It can be seen from the $p$ values of $<0.001$.
\end{abstract}

\section{KEY WORDS}

Emotion, user expertise, data, quality systems.

Enterprise Resource Planning (ERP) is a system used to integrate business processes in manufacturing and production, finance and accounting, sales and marketing, and human resources into one software system. The results of the information are stored in a comprehensive data warehouse that can be used by different parts of the business (Laudon et al., 2012). The importance of this system is explained by O'Brien (2015) that ERP is a backbone across corporate functions that integrates and automates many internal processes and information systems in terms of production, logistics, distribution, accounting, financial and human resources functions in the company. A good system must also be supported by good user skills, so that the information system applied can create good ERP system data quality (Compeau and Higgins, 1995); (Nelson and Cheney, 1987).

The ERP system is currently a system that is relied on by many companies to facilitate company activities and to present relevant data. Data quality problems become a major reason for companies to implement ERP systems. The system can function optimally if the data produced is of high quality. The better the quality of the data, the more relevant information will be produced so that the information is more useful for information users to become a tool in decision making.

Many companies are starting to switch to ERP systems from the previous system, this will certainly force employees to learn and understand the new system. In the process of understanding this system sometimes problems or conflicts arise that are impossible to avoid by ERP system users, which can cause emotion from system users. Emotions can affect the performance of system users, which of course will also affect the quality of system data generated. Venkatesh (2000); Beaudry and Pinsonneault (2010) argue that emotion becomes a major role in the interaction between a person and the information system, the emotions felt by the users of the system can negatively affect the use of the system. This influence can result in reduced data quality of the ERP system, so that the system built cannot provide optimal benefits.

User emotions can be minimized with the expertise of ERP users. This is supported by Leger et al. (2014) stating that users with expertise in system usage will change their outlook and reactions to emotions when they interact with the system. Therefore, companies began to implement specialized training in using the system, to minimize any errors in system input. 
The more expert users of the system, it is expected error in the system data is also getting smaller, so the company can obtain quality system data.

Research on the use of ERP systems has been done, especially regarding the quality of data resulting from the use of ERP systems and data processing systems. However, research on the role of user emotion in the use of ERP systems is still very rare, whereas user emotion is an important component of the use of the system so that the expected results can be achieved well. This is revealed by several studies that the emotions felt by users of ERP systems arising from high workloads and excessive anxiety can be detrimental to the use of information systems, especially at the time of system implementation (Venkatesh, 2000); (Beaudry and Pinsonneault, 2010). This is supported by Riedl et al. (2012) which suggests that an interruption in tasks when a person performs a system implementation can cause significant negative emotions.

Research on emotional influences on system data quality was carried out previously by several researchers. Ifinedo (2011) and Igbaria et al. (1995). Conceptually, these two studies support the view that the skills of the users of the system are related to the quality of ERP data generated in a company. Emotionally, according to Leger et al. (2014), expert users tend to use the data available to cope with stressful situations, so they can help them perform tasks well and can make optimal decisions. Conversely, the emotional response of novice users tends to avoid interaction with the system

With such a scope, the purpose of this study is to find out how the quality of ERP system data is influenced by the user's emotional response and to know whether the user's expertise is able to reduce the emotional impact on the quality of the ERP system data. Furthermore, the focus of this research is on the moderate role of user expertise on the relationship between user emotion and the quality of ERP system data. Emotional responses are known to affect the concentration of ERP system users, especially if someone has a workload that is too large. Decreasing concentration can cause errors in system data input which will affect the decline of ERP system data quality. However, these emotions can be minimized by the expertise of users in using an ERP system.

The first part of this study describes the literature and findings on emotions, user expertise, and their relation to the quality of ERP system data. The next section arranges relationships and hypotheses to test the relationship between emotions, user expertise, and ERP system data quality. The second part of this study examines the hypothesis proposed with data from 40 research respondents.

\section{LITERATURE REVIEW}

This study uses two main streams of literature to build models and hypotheses. The first flow is related to emotions and systems, the second flow is related to the expertise of the system users. We also examine the latest literature on user emotions and expertise on data quality of ERP systems.

Technology Acceptance Model (TAM). Technology Acceptance Model (TAM) is one of the models built to understand and analyze what factors affect the acceptability of the use of a computer technology (Davis, 1989); (Davis et al., 1989). TAM is adopted from the Theory of Reasoned Action (TRA) model on the basis of the theory of the reasonable action of a person in reaction, and the perception of something can determine the attitudes and behavior of the person.

Such reactions and perceptions of users of Information Technology (IT), can affect a person's attitude related to the acceptance of the information system. One of the influencing factors is the user's perception of ease of use and the benefits that can be obtained from the IT. This can affect the actions or reactions of IT users as a benchmark for the acceptance of the technology applied.

The TAM model developed from psychological theory that explains the behavior of computer users is basically influenced by belief, intention, attitude, and user behavior relationship. The TAM model has a purpose to explain what factors of user behavior can 
influence technology acceptance. Two variables that describe user attitudes toward technology acceptance are: ease of use, and usefulness.

Ease of use and usefulness can be attributed to how users respond in using IT as well as in using the system. This model illustrates that user acceptance of a system is affected by ease of use and usefulness.

The role of User Emotions in Information Systems. Damasio (1994) in Leger et al. (2014) defines emotion as a change of state of the body and brain triggered by a specific content response to perception, actuality, or memory related to a particular object or event of a person's brain system. Emotions will focus on the important events that occur.

Bechara and Damasio (2005) suggest that emotions provide implicit and explicit knowledge is a major factor in decision making as well as interaction between a person and his or her environmental condition. Emotion also plays a central role in one's work experience, especially when organizational transformation occurs such as the development of an ERP system.

A person who has emotional stability will have objectivity based on logic for problem solving. Emotional actions can degrade a person's performance, including decreased arousal, frequent truancy or not working, high blood pressure, gastrointestinal disturbances, and so on. This shows that a negative emotional state is a situation where a person experiences tension due to conditions that affect him. Furthermore, in the context of the work field, this can interfere with a person's performance in the company, so that it can affect the quality of the person's performance.

User Expertise Concepts. Whether the information system user is at the expert level or the beginner level becomes urgency in behaving on the information systems (Yang, 1997). As revealed by Tabatabai and Shore (2005), the difference between expert users and novice users of information systems is their strategy in finding information. In essence, expert users tend to use clear criteria to evaluate a site without over-navigating. Expert users also use monitoring progress and background knowledge about information retrieval. This positive attitude is also called one of the expert criteria. By having a positive attitude, ERP quality can be maintained with good quality without being affected by emotions.

In the context of emotional stability, it has been found that users with higher levels of computer self-efficacy spend less time making decisions, and they also use less information; In addition, their perception of the utility of the system and their satisfaction is greater (Hung, 2003). By having this type of attitude, expert employees will use the process of thinking analogically rather than beginners, who tend to use a trial and error approach that can cause negative emotions. Thus, the reason to train novice users of information systems is necessary to create good data quality ERP systems (Compeau and Higgins, 1995); (Nelson and Cheney, 1987).

Given these differences about how expert users and beginners behave towards new systems, good ERP quality can be generated by expert users. In addition to their knowledge and good skills on system usage, they also have a more stable emotional state that can lead them to faster and better work. In this case, the user's expertise can reduce the negative effects of emotions in using ERP systems properly.

\section{HYPOTHESIS DEVELOPMENT}

The main premise of this research is that an organization that has a culture that promotes innovation tends to be innovative, which, in turn, is likely to result in superior company performance achievement. The model is illustrated in Figure 1.

Emotions felt by users of ERP systems arising from high workloads and excessive anxiety can be detrimental to the use of information systems, especially at the time of system implementation (Venkatesh, 2000); (Beaudry and Pinsonneault, 2010). This is supported by Riedl et al. (2012) which suggests that an interruption in tasks when a person performs a system implementation can cause significant negative emotions.

Research on the effect of emotion on the quality of data system has been done before by some researchers (Ifinedo, 2011); (Igbaria et al., 1995). Conceptually, these two studies 
support the view that the skills of the users of the system are related to the quality of ERP data generated in a company. Emotionally, according to Leger et al. (2014), expert users tend to use the data available to cope with stressful situations, so they can help them perform tasks well and can make optimal decisions. In contrast, the emotional responses of novice users tend to avoid interaction with ERP systems in the context of decision making, resulting in less than optimal performance. Therefore, it can be drawn a thought that the user's emotions affect the quality of ERP system data.

H1: User emotion affects the quality of ERP system data.

Nelson and Cheney (1987) demonstrate that training novice users of software systems is important because it can have a significant effect on system implementation, in this case affecting the use of ERP systems. Beginner users are expected to learn more quickly about the right skills and behavior responses in order to use the system properly and correctly. In this process, task control is required.

With regard to ERP system applications, an important aspect for novice users to learn relevant sources of information about the system will affect the decision making done by users of the system (McAfee, 2006).

This is also emphasized by Bano and Zowghi (2013); Guimaraes et al. (2004) who argue that the expertise of each user individually has a positive relationship with the quality of the system. More experienced and / or more trained users are more likely to participate actively in system development and have lower levels of stress. Indirectly, better communication with system developers will be established and it can improve the quality of corporate ERP data.

We can know that the response of novice users and expert users in the implementation of the system is very different. Expert users tend to be more prudent in controlling their emotions, so as to produce better system data quality than novice users.

H2: User expertise reduces the relationship between user emotion and ERP system data quality.

Figure 1 below presents this research model. This study focuses on examining the role of emotion for information systems during the use of ERP systems based on user expertise of the system.

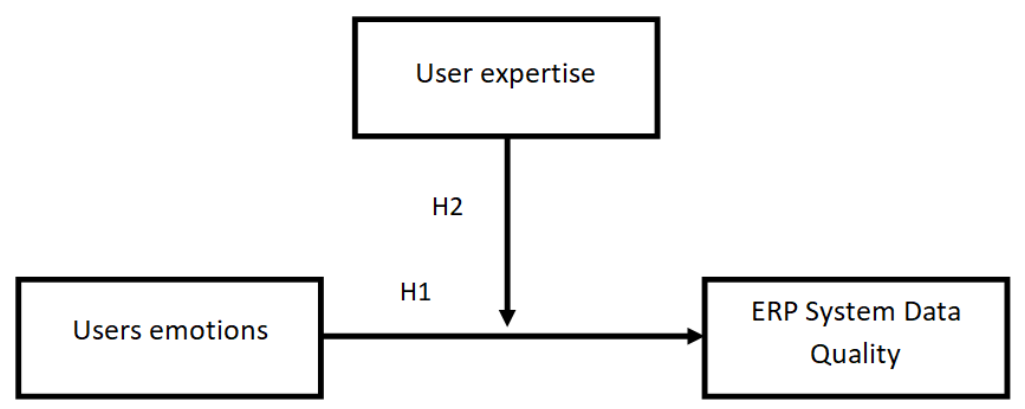

Figure 1 - Research Model

\section{METHODS OF RESEARCH}

Population and Sample. Data from this study were obtained from questionnaires distributed to employees of ERP system users working in PT. Pembangunan Pemerintah, Tbk which is one of the ERP user companies in Indonesia. Employees of ERP system users are selected because they are the parties directly involved with the use of ERP systems or them as end users of ERP systems. This study focuses on the quality of ERP system data that they input depends on the emotional conditions and expertise they have regarding the ERP system. The procedure for determining the sample is done by convenience sampling, which is a non-random sampling technique, but appoints companies that are expected to provide information related to this research. A total of 40 responses were obtained for this study. 
No studies or literature that examines the emotions and relationships with the ERP system in Indonesia, especially at PT. Pembangunan Pemerintah, Tbk. And there are only a few studies that examine the relationship between the variables that exist in this study with information systems. Therefore, the results of this study can be new findings in academics.

Operational Definition and Variable Measurement:

Independent Variables. The questionnaire used contains questions to measure variables in this study. In the questionnaire, the question about this independent variable is in the third section. User emotion was measured by a questionnaire developed by Igbaria and Chakrabarti (1990). The instrument asks individuals to show their agreement or disagreement with 5 questions that reflect the participation and conflict that may have been experienced by respondents during the ERP system. Response options range from (1) strongly disagree to (5) strongly agree.

Moderate Variables. The moderating variable in this study was measured using a questionnaire. Questions about this moderating variable are in the first and second parts of the questionnaire. User expertise was measured by a questionnaire developed by Igbaria and Chakrabarti (1990). Through 6 questions in sections one and 4 of the question there is part two of the questionnaire asking individuals to show their agreement or disagreement regarding the experience and training of information systems related to accounting that may have been followed by respondents. Response options range from (1) strongly disagree to (5) strongly agree.

Dependent Variables. The quality of ERP system data is measured by a questionnaire developed by (Igbaria and Chakrabarti, 1990). Questions in the questionnaire asked individuals to show their agreement or disagreement with 5 questions that reflect the quality of the system information. Response options range from (1) strongly disagree to (5) strongly agree.

\section{RESULTS AND DISCUSSION}

Profile of respondent. Information on job title, length of work, last education of respondents are presented in Table 1. Job positions of respondents in the study are not dominated by specific positions. Most respondents have varied work experience, ranging from 1 to 34 years. Table 2 presents the demographic characteristics of respondents that show the dominance of male respondents to women. Most respondents have a bachelor's degree.

Reliability, factor analysis, and average value. Table 3 shows the ways and standard deviations of responses to items that measure emotion, system expertise and system data quality.

According to the results of the reliability analysis, items that have a total item correlation value lower than 0.40 must be eliminated. In this study for items from the user's expertise scale namely EXP2 - EXP5 must be eliminated. Nunnally (1978) states that the loading cut-off used are 0.40 assuming that all loading factors that have values above 0.54 are significant. Therefore, the results of composite reliability measurements in this study indicate that all variables have a composite reliability value greater than 0.70 . It can be concluded that all variables in this study are reliable and reliable for use in further analysis.

Hypothesis testing. The hypothesis that has been proposed will be tested using the Structural Equation Model (SEM) model with the Partial Least Square (PLS) analysis model. PLS analysis was tested using the help of WarpPLS 5.0 software for windows to examine the influence between emotions which is moderated by the user's expertise on the quality of the system data.

Table 5 shows that all proxies have an outer loading factor value greater than 0.5 . It can be concluded that all indicators are eligible to be an indicator that can reflect each of the corresponding variables.

The measurement of discriminant validity is to compare the Average Variance Extracted (AVE) square value of each construct with the correlation between the other constructs in the model. Recommended AVE value must be greater than 0.5. In Table V 
shows the AVE value of each variable greater than 0.5 , so it can be concluded that the variables used are valid and reliable.

Table 1 - Profile of Respondents

\begin{tabular}{lcc}
\hline & $\mathrm{n}$ & $\%$ \\
\hline Position & 6 & $15 \%$ \\
Site Administration Manager & 5 & $13 \%$ \\
Accounting Staff & 7 & $18 \%$ \\
Logistics & 6 & $15 \%$ \\
Site Engineer Manager & 1 & $3 \%$ \\
Officer, VAT Section & 4 & $10 \%$ \\
Officer, Accounting Section & 1 & $3 \%$ \\
Officer, Accounts Payable Section & 1 & $3 \%$ \\
Officer, Cashier Section & 2 & $5 \%$ \\
Officer, Tax Section & 2 & $5 \%$ \\
Officer, Production and Cost Control Section & 2 & $5 \%$ \\
Manager, Head of Production and Cost Control Section & 2 & $5 \%$ \\
Manager, Head of Purchasing Section & 1 & $3 \%$ \\
Manager, Head of Tax Section & 29 \\
Length of work & $29 \%$ \\
$1-10$ & 3 & $73 \%$ \\
$11-20$ & $2 \%$ \\
>1-30 30 & $2 \%$ \\
\hline
\end{tabular}

Table 2 - Demographics Sample

\begin{tabular}{lll}
\hline & $\mathrm{N}$ & $\%$ \\
\hline Gender & & \\
Man & 33 & $83 \%$ \\
Woman & 7 & $18 \%$ \\
Last education & & $15 \%$ \\
SMU & 6 & $3 \%$ \\
D3 & 1 & $83 \%$ \\
S1 & 33 & \\
\hline
\end{tabular}

Table 3 - The average and standard deviation of the item

\begin{tabular}{|c|c|c|}
\hline items & $\begin{array}{l}\text { mean } \\
\text { Value }\end{array}$ & SD \\
\hline \multicolumn{3}{|l|}{ User expertise } \\
\hline I understand how to get the data and information required. & 4.15 & 0.48 \\
\hline I know the information is relevant to take that into consideration in making a decision. & 4.28 & 0.6 \\
\hline $\begin{array}{l}\text { I am easy to search for the causes of errors and can provide recommendations to eliminate / minimize } \\
\text { causes. }\end{array}$ & 3.95 & 0.68 \\
\hline I'm easy to run existing accounting information system thanks to the training undertaken. & 4.08 & 0.73 \\
\hline I feel the training makes it easy for me to make judgments related to the available data. & 4.35 & 0.62 \\
\hline I feel that there is facilitate training in detecting errors in the data provided. & 4.18 & 0.64 \\
\hline I understand the accounting cycle contained in the company. & 4.03 & 0.77 \\
\hline I understand the accounting rules applicable to the industrial sector my company & 3.88 & 0.76 \\
\hline I know the accounting information system in the company in accordance with applicable regulations. & 3.90 & 0.71 \\
\hline $\begin{array}{l}\text { I know the existing accounting information systems contributes to more easily understand the accounting } \\
\text { cycle. }\end{array}$ & 4.03 & 0.73 \\
\hline \multicolumn{3}{|l|}{ emotion } \\
\hline In my opinion, the existing information systems pose a burden to learn more & 2.90 & 1.15 \\
\hline In my opinion, the existing information systems cause trouble in operation. & 2,63 & 0.93 \\
\hline In my opinion, the information system provides workload becomes more & 2.35 & 0.83 \\
\hline $\begin{array}{l}\text { In my opinion, the existing information systems caused disagreement between colleagues associated with } \\
\text { the account in the work }\end{array}$ & 2.85 & 1.00 \\
\hline $\begin{array}{l}\text { In my opinion, the existing information systems lead to differences in perception between leaders and } \\
\text { employees associated with the account in the work } \\
\text { Data Quality }\end{array}$ & 2.85 & 1.08 \\
\hline In my opinion, the information conveyed by the information system is clear and easy to understand & 3.83 & 0.55 \\
\hline In my opinion, the information conveyed by the information system is accurate. & 3.78 & 0.7 \\
\hline In my opinion, the information conveyed by the information system facilitates the work & 4.18 & 0.64 \\
\hline In my opinion, the information conveyed by the information system is reliable information. & 3.98 & 0.62 \\
\hline In my opinion, the information conveyed by the information system is the relevant information & 4.00 & 0.60 \\
\hline
\end{tabular}

Based on the results in Table 6 it can be concluded that the emotional variable does not affect the quality of the system data. This can be seen based on p-values of 0.191 where the value is greater than 0.05 . Based on the estimated value of the regression coefficient 
(path coefficient), which is equal to 0.132 . The positive sign of the regression coefficient shows the unidirectional relationship between the emotion and the quality of the system data, where if the emotion increases once, then the system data quality will increase by 0.132 times. It can be concluded that the hypothesis 1 (one) that emotional variables do not affect the data quality of ERP systems.

Table 4 - The results of the factor analysis and reliability analysis

\begin{tabular}{|c|c|c|c|}
\hline & & $\begin{array}{l}\text { Outer } \\
\text { Loading }\end{array}$ & Reliability \\
\hline $\exp 1$ & I understand how to get the data and information required. & 0.587 & 0.885 \\
\hline EXP7 & I understand the accounting cycle contained in the company. & 0.875 & \\
\hline EXP8 & $\begin{array}{l}\text { I understand the accounting rules applicable to the industrial sector my } \\
\text { company }\end{array}$ & 0.863 & \\
\hline EXP9 & $\begin{array}{l}\text { I know the accounting information system in the company in accordance with } \\
\text { applicable regulations. }\end{array}$ & 0.903 & \\
\hline EXP10 & $\begin{array}{l}\text { I know the existing accounting information systems contributes to more easily } \\
\text { understand the accounting cycle. }\end{array}$ & 0.627 & \\
\hline EMO1 & In my opinion, the existing information systems pose a burden to learn more. & 0.746 & 0.934 \\
\hline EMO2 & In my opinion, the existing information systems cause trouble in operation. & 0.917 & \\
\hline EMO3 & In my opinion, the information system provides workload be increased. & 0.862 & \\
\hline EMO4 & $\begin{array}{l}\text { In my opinion, the existing information systems caused disagreement } \\
\text { between colleagues in the work associated with the account. }\end{array}$ & 0.908 & \\
\hline EMO5 & $\begin{array}{l}\text { In my opinion, the existing information systems lead to differences in } \\
\text { perception between leaders and employees associated with the account in } \\
\text { the work. }\end{array}$ & 0.854 & \\
\hline QUA1 & $\begin{array}{l}\text { In my opinion, the information conveyed by the information system is clear } \\
\text { and easy to understand. }\end{array}$ & 0.642 & 0.848 \\
\hline QUA2 & $\begin{array}{l}\text { In my opinion, the information conveyed by the information system is } \\
\text { accurate. }\end{array}$ & 0.826 & \\
\hline QUA3 & $\begin{array}{l}\text { In my opinion, the information conveyed by the information system facilitates } \\
\text { the work. }\end{array}$ & 0.652 & \\
\hline QUA4 & $\begin{array}{l}\text { In my opinion, the information conveyed by the information system is reliable } \\
\text { information. }\end{array}$ & 0.740 & \\
\hline QUA5 & $\begin{array}{l}\text { In my opinion, the information conveyed by the information system is relevant } \\
\text { information. }\end{array}$ & 0.765 & \\
\hline
\end{tabular}

Table 5 - Value Outer Loading and AVE

\begin{tabular}{|l|l|l|l|l|l|}
\hline Variables & Indicator & Outer Loadings & AVE & composite Reliability & Conclusion \\
\hline EXP & EXP 1 & 0.587 & & & Significant \\
& EXP 7 & 0.875 & \multirow{2}{*}{0.612} & 0.934 & Significant \\
& EXP 8 & 0.863 & & & Significant \\
& EXP 9 & 0.903 & & Significant \\
& EXP 10 & 0.627 & & & Significant \\
\hline EMO & EMO 1 & 0,746 & 0.739 & 0.885 & Significant \\
& EMO 2 & 0.917 & & Significant \\
& EMO 3 & 0.862 & & & Significant \\
& EMO 4 & 0.908 & & Significant \\
& EMO 5 & 0.854 & & & Significant \\
\hline QUA & QUA 1 & 0.642 & & Significant \\
& QUA 2 & 0.826 & 0.531 & 0.848 & Significant \\
& QUA 3 & 0.652 & & Significant \\
& QUA 4 & 0.740 & & & Significant \\
\hline & QUA 5 & 0.765 & & \\
\hline
\end{tabular}

Table 6 - Path Analysis

\begin{tabular}{|l|l|l|}
\hline Path $\longrightarrow$ QUA & Path Coefficient & P-Value \\
\hline $\mathrm{EMO} \longrightarrow$ QUA & 0,132 & 0,191 \\
\hline $\mathrm{EXP}^{*} \mathrm{EMO}$ & 0,468 & $<0,001$ \\
\hline
\end{tabular}

Whereas for user skill variable have a significant positive effect to system data quality. It can be seen from the $p$-values of $<0.001$. Based on the estimated value of the regression coefficient (path coefficient), which is equal to 0.468 . The positive sign of the regression 
coefficient shows a direct relationship between the user's expertise and the quality of the system data, which if the user's expertise increases once, then the system data quality will increase by 0.468 times. It can be concluded that the hypothesis of 2 (two) user expertise variables has a significant positive effect on the quality of ERP system data.

The results of testing hypothesis 1 state that the user's emotions do not affect the data quality of the ERP system. Basically, the implementation of new system or work given to the employees is the responsibility that must be completed by the employees and not become the work load. So in the use of any system, employees must be responsible and do not consider the work as a burden. Therefore, emotion does not affect the quality of ERP system data.

Hypothesis 2 states that user expertise reduces the relationship between users' emotions and ERP system data quality. The results showed a significant positive effect on the quality of system data. The results of this study are in line with research conducted by Bano and Zowghi (2013), Guimaraes et al. (2004) which states that the expertise of each user individually has a positive relationship with the quality of the system. More experienced and / or more trained users are more likely to participate actively in system development and have lower levels of stress. Indirectly, better communication with system developers will be established and it can improve the quality of corporate ERP data.

More skilled users will tend to be able to control their emotions, supported by the ability of those qualified to use the system then the possibility of a mistake in the use of the system the smaller. This can affect the quality of system data to be generated.

\section{CONCLUSION}

This study aims to find out how the quality of ERP system data is influenced by the user's emotional response and whether the user's expertise is able to reduce the emotional impact on the data quality of the ERP system. In this study we found negative results from the influence of users' emotions on ERP system data quality. This is because the use of the system is a responsibility for all users of the system, not a workload for users. As for user expertise, our research obtained positive results in accordance with the hypothesis formulated. Our findings indicate that the ability of users of the system is essential to support the quality of the ERP system data. Expert users can understand the cycle of the system and understand how to obtain data for the system and understand relevant information as a consideration in making decisions. We find that this expertise is gained through training conducted to improve the ability to use the system. Our conclusion emphasizes that emotions can be reduced with the expertise of the users of the ERP system so that the quality of the resulting data is relevant.

Limitations in this study are the use only one company as a sample of research, so less able to generalize the results of these findings. Therefore, further research can use more than one company to make the results more relevant.

\section{REFERENCES}

1. Bano, Muneera, \& Zowghi, Didar. 2013. User Involvement in Software Development and System Success: A Systematic Literature Review. Paper presented at the Proceedings of the 17th International Conference on Evaluation and Assessment in Software Engineering.

2. Beaudry, Anne, \& Pinsonneault, Alain. 2010. The Other Side of Acceptance: Studying the Direct and Indirect Effects of Emotions on Information Technology Use. MIS quarterly No. pp. 689-710.

3. Bechara, Antoine, \& Damasio, Antonio R. 2005. The Somatic Marker Hypothesis: A Neural Theory of Economic Decision. Games and economic behavior Vol. 52 No. 2 pp. 336-372.

4. Compeau, Deborah R, \& Higgins, Christopher A. 1995. Computer Self-Efficacy: Development of a Measure and Initial Test. MIS quarterly No. pp. 189-211. 
5. Damasio, Antonio R. 1994. Descartes' Error: Emotion, Reason, and the Human Brain.

6. Davis, Fred D. 1989. Perceived Usefulness, Perceived Ease of Use, and User Acceptance of Information Technology. MIS quarterly No. pp. 319-340.

7. Davis, Fred D, Bagozzi, Richard P, \& Warshaw, Paul R. 1989. User Acceptance of Computer Technology: A Comparison of Two Theoretical Models. Management science Vol. 35 No. 8 pp. 982-1003.

8. Guimaraes, Tor, Staples, D Sandy, \& McKeen, James D. 2004. Empirically Testing Some Main User-Related Factors for Systems Development Quality. QUality Control and Applied StatistiCS Vol. 49 No. pp. 333-336.

9. Hung, Shin-Yuan. 2003. Expert Versus Novice Use of the Executive Support Systems: An Empirical Study. Information \& Management Vol. 40 No. 3 pp. 177-189.

10. Ifinedo, Princely. 2011. Internal It Knowledge and Expertise as Antecedents of Erp System Effectiveness: An Empirical Investigation. Journal of Organizational Computing and Electronic Commerce Vol. 21 No. 1 pp. 1-23.

11. Igbaria, Magid, \& Chakrabarti, Alok. 1990. Computer Anxiety and Attitudes Towards Microcomputer Use. Behaviour \& Information Technology Vol. 9 No. 3 pp. 229-241.

12. Igbaria, Magid, Guimaraes, Tor, \& Davis, Gordon B. 1995. Testing the Determinants of Microcomputer Usage Via a Structural Equation Model. Journal of management information systems Vol. 11 No. 4 pp. 87-114.

13. Laudon, Kenneth C. et al. 2012. Management Information Systems: Managing the Digital Firm, Seventh Canadian Edition: Pearson.

14. Leger, Pierre-Majorique, Riedl, René, \& vom Brocke, Jan. 2014. Emotions and Erp Information Sourcing: The Moderating Role of Expertise. Industrial Management \& Data Systems Vol. 114 No. 3 pp. 456-471.

15. McAfee, Andrew. 2006. Mastering the Three Worlds of Information Technology. Harvard Business Review Vol. 84 No. 11 pp. 141.

16. Nelson, R Ryan, \& Cheney, Paul H. 1987. Training End Users: An Exploratory Study. MIS quarterly No. pp. 547-559.

17. Nunnally, JC. 1978. Psychometric Theory. Mc Graw-Hill Publ Co. New York No. pp.

18. O'Brien, Tony. 2015. 'Accounting'for Data Quality in Enterprise Systems. Procedia Computer Science Vol. 64 No. pp. 442-449.

19. Riedl, René, Kindermann, Harald, Auinger, Andreas, \& Javor, Andrija. 2012. Technostress from a Neurobiological Perspective. Business \& Information Systems Engineering Vol. 4 No. 2 pp. 61-69.

20. Tabatabai, Diana, \& Shore, Bruce M. 2005. How Experts and Novices Search the Web. Library \& information science research Vol. 27 No. 2 pp. 222-248.

21. Venkatesh, Viswanath. 2000. Determinants of Perceived Ease of Use: Integrating Control, Intrinsic Motivation, and Emotion into the Technology Acceptance Model. Information systems research Vol. 11 No. 4 pp. 342-365.

22. Yang, Shu Ching. 1997. Information Seeking as Problem-Solving Using a Qualitative Approach to Uncover the Novice Learners' Information-Seeking Processes in a Perseus Hypertext System. Library \& Information Science Research Vol. 19 No. 1 pp. 71-94. 